\title{
Ansiedade e Depressão em Residentes em Radiologia e Diagnóstico por Imagem
}

\section{Anxiety and Depression Among Medical Residents in Radiology and Diagnostic Imaging}

\author{
Glauce Cerqueira Corrêa da Silva ${ }^{I}$ \\ Hilton Augusto Koch ${ }^{I I}$ \\ Evandro Guimarães de Sousa ${ }^{I}$ \\ Emerson Gasparetto ${ }^{I}$ \\ Rogério Christiano Buys ${ }^{I}$
}

\section{PALAVRAS-CHAVE \\ - Residência Médica. \\ - Internato e Residência \\ - Ansiedade. \\ - Depressão.}

\section{KEY-WORDS}

- Medical Residence.

- Internship and Residency

- Anxiety.

- Depression.

\section{Recebido em: 16/03/2009}

Reencaminhado em: 07/07/2009

Aprovado em: 06/08/2009
${ }^{I}$ Universidade Federal do Rio de Janeiro, Rio de Janeiro, RJ, Brasil.

"Universidade Federal do Rio de Janeiro, Rio de Janeiro, RJ, Brasil; Santa Casa de Misericórdia do Rio de Janeiro, Rio de Janeiro, RJ, Brasil. 


\section{INTRODUÇÃO}

Para Pereira Filho ${ }^{1}$, a expressão Residência Médica surgiu quando médicos recém-formados passaram a morar nos hospitais por períodos predeterminados, em dedicação exclusiva, com o objetivo de adquirir habilidades que lhes oferecessem mais segurança durante o exercício profissional. Admite-se que os primeiros programas de Residência Médica surgiram no Hospital John Hopkins, nos Estados Unidos, em Cirurgia e Clínica Médica.

No Brasil, esta modalidade de treinamento iniciou-se na década de 1940. Com a competitividade no mercado de trabalho, houve a necessidade de ampliar as competências adquiridas durante o curso de graduação em Medicina. Além disso, o aumento do número de escolas médicas, no final dos anos 1960 e década de 1970, determinou a ampliação de programas de Residência Médica, devido a maior procura deste treinamento por egressos dos cursos de Medicina. Alguns desses programas não poderiam ser considerados treinamento em serviço, devido a inúmeras deficiências apresentadas. Portanto, houve necessidade de se criar a Comissão Nacional de Residência Médica (CNRM), com a atribuição de regulamentar esta modalidade de curso de pós-graduação para médicos no Brasil $^{2}$. A Comissão estabeleceu normas e requisitos mínimos para o credenciamento de programas de Residência Médica em todo o território nacional, inclusive os relacionados com a especialidade de Radiologia e Diagnóstico por Imagem³ Im $^{3}$

Os cursos de especialização encontram-se regulamentados pela Resolução CNE/CES no 01/20074, que determina a carga horária mínima de 360 horas e a frequência de, no mínimo, $75 \%$ às atividades programadas. $\mathrm{O}$ corpo docente destes cursos deverá ser constituído por professores especialistas ou de reconhecida capacidade técnico-profissional, sendo que $50 \%$ destes, pelo menos, deverão apresentar titulação de mestre ou de doutor, obtido em programa de pós-graduação stricto sensu, reconhecido pelo Ministério da Educação.

É exigido trabalho de conclusão de curso ou monografia para aprovação final do aluno. Ao término deste curso, o aluno aprovado fará jus a um certificado de conclusão, que é aceito por várias sociedades de especialidades, como pré-requisito para a concessão do título de especialista.

Esta modalidade de curso tem sido utilizada por determinadas instituições como substituto de programas de Residência Médica, uma vez que não são estipulados prazos para a sua conclusão, nem carga horária máxima. Por outro lado, não existe a necessidade do cumprimento dos direitos dos médi-

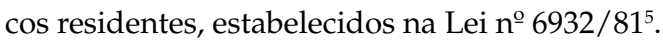

Para Glasser ${ }^{6}$, o trabalho é o componente que define nossas vidas, pois não podemos ser vítimas de uma escolha. De- vemos assumir responsabilidade por elas, ou seja, devemos estar satisfeitos com a profissão escolhida para obtermos sucesso e satisfação pessoal.

O porquê da escolha do curso de graduação em Medicina, a seleção da Radiologia e Diagnóstico por Imagem, a pretensão salarial, dificuldades e facilidades encontradas no exercício da profissão, idealização versus realidade da profissão e o que desejam alcançar como radiologistas são algumas das escolhas que estes futuros profissionais têm que realizar, muitas vezes, sem a necessária maturidade psicológica, o que os tornam ainda mais inseguros e ansiosos com seu futuro.

De acordo com De $\mathrm{Marco}^{7}$, a realidade é "cruel" com estes estudantes, que, quando escolhem ser médicos, o fazem baseados no seu mundo pessoal. É uma idealização, e, como não conseguem lidar com essa dura realidade, se desiludem. "A realidade é forte, poderosa e sofrida".

Millan et al. ${ }^{8}$ afirma que, após estas escolhas, o aluno de Medicina, durante o curso de graduação, tem seus primeiros contatos com os pacientes. Isto também gera muitos temores, que vêm, principalmente, de suas inseguranças pessoais. É por isso que a figura de um instrutor/professor é importante nesses primeiros passos, para ajudar a determinar, a formar esses futuros médicos, junto com suas identidades profissionais. A relação professor-aluno será um reflexo da relação estudantepaciente.

Os estudantes também não são preparados para a relação humana que terão com os pacientes. O que receberam como instrução de seus professores não é suficiente para aliviar suas ansiedades e temores, fazendo com que se sintam, muitas vezes, mais exploradores do que doadores nesta relação com os pacientes.

Os tutores desenvolvem um papel importante na vida do estudante de Medicina. São eles os responsáveis pelo suporte nas dificuldades e vivências profissionais, muitas vezes violentas. Isto não permite que as defesas psíquicas ganhem espaço. No dia a dia, se o estudante de Medicina não tiver o suporte de um profissional para lidar com as angústias, surgem mecanismos de defesa, como:

- Negação: recurso do ego enfraquecido, no qual a realidade é percebida e reconhecida por todos, menos por aquele que sofre ou sofrerá suas consequências e que nega a realidade;

- Dissociação: sofrimento da mente devido aos males do corpo, uma defesa do ego contra a ansiedade, originada geralmente de desejos de natureza física reprimidos. Esses conflitos se exteriorizam por meio de sintomas ou distúrbios físicos, com frequência carregados de simbolização. Também pode ocorrer como resposta a tensões insuportáveis que têm, por essa via, sua válvula de escape. É a perda parcial ou completa 
da integração normal entre memória, consciência de identidade, sensação imediata e controle dos movimentos corporais;

- Intelectualização: processo pelo qual o sujeito procura dar uma formulação discursiva aos seus conflitos e emoções, de modo a dominá-los. Caso se tornem frequentes, parte dos estudantes se alienam do aspecto humano e se tornam profissionais frios, estressados e sem realização pessoal, com uma autoimagem de onipotência, diferente da que tanto almejaram no início do curso.

Em função das angústias e comportamentos negativos encontrados nos médicos residentes e especializandos, incluindo aqueles em formação em Radiologia e Diagnóstico por Imagem, que tanto desestruturam o desempenho deles durante o programa de treinamento, é necessário verificar os níveis de ansiedade e de depressão destes alunos, para humanizar tanto sua carreira profissional e pessoal quanto a relação com pacientes, colegas de profissão, professores e equipe de saúde - enfim, tudo que promova a saúde física e mental destes estudantes e suas relações com os outros.

\section{OBJETIVO}

Identificar os níveis de ansiedade e depressão, e sua interferência na motivação e no desempenho curricular dos alunos dos cursos de especialização em Residência Médica em Radiologia e Diagnóstico por Imagem.

\section{MATERIAL E MÉTODO}

Foi elaborado um questionário com 11 perguntas referentes ao perfil psicossocial, percepção do nível de relacionamento, nível de aprendizagem e dificuldades psicológicas percebidas por estes especializandos e médicos residentes de um curso de pós-graduação em Radiologia e Diagnóstico por Imagem na cidade do Rio de Janeiro. Também foi utilizada a Escala Hospitalar de Ansiedade e Depressão (HADS), com sete itens que avaliam a ansiedade (HADS-A) e sete que analisam a depressão (HADS-D). Para se detectar a frequência da ansiedade e da depressão coletadas nos itens do HADS, foram adotados os pontos de corte indicados por Zigmond e Snaith ${ }^{9}$ e que são recomendados para as duas subescalas:

- HAD - ansiedade: sem ansiedade de 0 a 8, com ansiedade $\geq$ a 9 (maior ou igual);

- HAD - depressão: sem depressão de 0 a 8, com depressão $\geq$ a 9 (maior ou igual).

Esse questionário foi aplicado em especializandos e médicos residentes de um curso de pós-graduação em Radiologia e Diagnóstico por Imagem do Rio de Janeiro. A participação deles foi voluntária e todos assinaram o Termo de Consenti- mento Livre e Esclarecido. São três turmas do ano de 2007 e três turmas do ano de 2008 de Residência Médica na especialidade. Este questionário foi aplicado a cada seis meses durante um período de dois anos. O primeiro grupo que participou da pesquisa iniciou o curso no primeiro semestre de 2007, o segundo iniciou no primeiro semestre de 2006, e o terceiro em 2005. Foram investigados 76 alunos do ano de 2007 e 73 alunos do ano de 2008, totalizando 149 alunos nos dois anos, entre eles médicos residentes e especializandos.

\section{RESULTADOS}

Comparação dos resultados e análise das respostas dos questionários aplicados em 2007 e 2008 aos 149 alunos do curso de especialização e dos médicos residentes em Radiologia e Diagnóstico por Imagem.

\section{Distribuição quanto ao sexo dos alunos entrevistados}

Dos 149 indivíduos entrevistados, 77 são do sexo feminino $(52 \%)$ e 72 são do sexo masculino ( $48 \%)$.

\section{Distribuição etária dos dois grupos de alunos entrevistados}

Dos 149 alunos entrevistados, 80\% encontravam-se na faixa de 20 a 30 anos, $19 \%$ dos médicos entre 31 e 40 anos, e apenas $1 \%$ acima de 50 anos.

\section{Estado civil dos alunos entrevistados}

Dos alunos entrevistados, $82 \%$ são solteiros, $17 \%$ casados e $1 \%$ separado.

Tabela 1

Percepção dos especializandos e médicos residentes em Radiologia e Diagnóstico por Imagem sobre relacionamento com a equipe

\begin{tabular}{lcccc}
\hline $\begin{array}{c}\text { Níveis de } \\
\text { percepção/equipe }\end{array}$ & Muito bom & Médio & Péssimo & Total \\
\hline Chefe do de serviço & 97 & 52 & 0 & 149 \\
Estafe & 132 & 17 & 0 & 149 \\
Secretárias & 121 & 25 & 3 & 149 \\
\hline
\end{tabular}

\section{Chefe do serviço (Tabela 1)}

Para os 149 alunos entrevistados, nas quatro aplicações deste questionário, $65 \%$ têm um relacionamento muito bom e $35 \%$ têm um relacionamento de nível médio, e nenhum aluno com relacionamento péssimo.

No grupo dos médicos, o motivo mais assinalado para um bom relacionamento $(70 \%)$ foi o fato de o chefe do serviço dar 
Tabela 2

Percepção dos alunos em Radiologia e Diagnóstico por Imagem sobre o ensino

\begin{tabular}{|c|c|c|c|c|c|c|}
\hline Níveis de percepção/ensino & Ruim & Regular & Bom & Muito bom & Excelente & Total \\
\hline Aprendizagem & 0 & 18 & 93 & 36 & 2 & 149 \\
\hline Seminários & 0 & 16 & 94 & 24 & 15 & 149 \\
\hline Professores & 0 & 6 & 37 & 82 & 24 & 149 \\
\hline
\end{tabular}

bons conselhos, incentivar o estudo, propiciar a aproximação, tornando o ambiente de trabalho uma segunda moradia, receber bem e orientar os alunos, ser atencioso e dar a oportunidade de os alunos expressarem suas vontades. Outro motivo apontado por $23 \%$ dos alunos foi o distanciamento do chefe do serviço. E 7\% registraram diversos motivos, entre eles nunca encontrar o chefe do serviço, estar no serviço sempre ocupado com os exames e não ter tido necessidade de falar com o chefe.

\section{Estafe (Tabela 1)}

De acordo com $89 \%$ dos alunos, o relacionamento com o estafe é muito bom devido à atenção dispensada, às orientações, à disponibilidade para esclarecimentos e por transmitirem experiência e conhecimentos. Apenas $11 \%$ dos alunos assinalaram que o relacionamento é médio devido ao pouco contato com o estafe.

\section{Secretárias (Tabela 1)}

A maioria dos alunos (81\%) afirma ter bom relacionamento com estas profissionais, pois sempre são educadas, atenciosas, prestativas, solícitas e esclarecedoras das dúvidas em relação ao serviço. Para 17\% destes alunos, o relacionamento é médio, por não terem contato com elas. Entretanto, 2\% constatam um péssimo relacionamento porque algumas estão sempre mal-humoradas e sem paciência.

\section{Nível de aprendizagem (Tabela 2)}

Dos alunos entrevistados, $62 \%$ consideram ter bom nível de aprendizagem, pois aproveitam bem os temas práticos discutidos em aulas ou seminários, considerando-os excelentes, e não aproveitam mais por não terem mais tempo de estudar ou por se sentirem ansiosos e desanimados. Vinte e quatro por cento consideram ter um nível de aprendizagem muito bom, atribuindo isto ao fato de se sentirem bem aceitos pelo estafe, médicos residentes e estagiários mais experientes, o que facilita a aprendizagem. Somente $2 \%$ consideram ter um nível de aprendizagem excelente porque têm ótimo aproveitamento das aulas teóricas e práticas, como também dos seminários. E 12\% consideram ter um nível de aprendi- zagem regular, pois acham que o número de integrantes do estafe é pequeno, o que os atrapalha. Contudo, julgam que aproveitam bem as aulas expositivas e os grupos de discussões sobre os vários temas, consideram ter boa atuação no serviço e conseguem fazer uma boa associação entre atividades teóricas e práticas.

\section{Nível dos seminários (Tabela 2)}

A maioria dos alunos (89\%) avaliou que os seminários estão com bom nível porque estimulam a estudar, as aulas são excelentes, os temas são bem apresentados e os motivam a estudar, pela atualização dos temas, possibilitam uma troca de conhecimentos muito rica entre alunos e estafe, os temas são básicos e para todos os níveis de aprendizagem. O nível de apresentação está excelente, tanto dos médicos residentes quanto dos professores, o que possibilita um bom treinamento para a prova do Colégio Brasileiro de Radiologia. Onze por cento dos alunos consideram os seminários regulares porque julgam que os temas não são básicos e não são para todos os níveis de aprendizagem.

\section{Nível dos professores (Tabela 2)}

Dezesseis por cento dos alunos avaliam os professores como excelentes, $55 \%$ como muito bons, e $25 \%$ como bons, devido ao excelente padrão de qualificação, competência, alto nível de conhecimento, por serem dedicados, terem disponibilidade para ajudar, possuírem excelente didática, serem muito atenciosos e objetivos. Os outros $4 \%$ como regulares, pois esperavam mais dos professores.

Tabela 3

Quanto ao tempo para o estudo individual durante a jornada de atividades

\begin{tabular}{lc}
\hline Tempo de estudo/jornada de atividades & № de alunos \\
\hline 1 a 2 horas de estudo & 116 \\
3 a 4 horas de estudo & 28 \\
Mais de 5 horas & 5 \\
\hline Total & 149 \\
\hline
\end{tabular}


Conforme a Tabela 3, dos 149 alunos entrevistados, 78\% estudam de uma a duas horas por dia algum tema discutido durante o dia ou de acordo com assuntos abordados no serviço ou nos seminários. Também utilizam este tempo para elaboração de resumos, leitura de artigos científicos na internet ou em livros, comparando imagens radiológicas obtidas com aquelas contidas em atlas de Radiologia. Destes, 19\% estudam de três a quatro horas por dia. Além de usarem as mesmas estratégias descritas acima, utilizam atividades práticas e programas de educação continuada da Sociedade Brasileira de Radiologia. Apenas 3\% estudam mais de cinco horas por dia.

\section{Quando procurar um psicólogo}

Dos alunos avaliados, $14 \%$ procurariam um psicólogo a fim de pedir ajuda para controlar a ansiedade presente no dia a dia do médico; $12 \%$ para maior orientação em seus conflitos de interesses; e 10\% quando se sentissem tristes, angustiados e irritados.

\section{Escala Hospitalar de Ansiedade e Depressão (HADS)}

$\mathrm{Na}$ escala de HADS, cada item pode ser pontuado de zero a três, sendo a pontuação de 21 a máxima para cada escala (ansiedade e depressão). Para se detectar a frequência da ansiedade e da depressão coletadas nos itens da HADS, foram adotados os pontos de corte indicados por Zigmond e Snaith ${ }^{9}$, recomendados para as duas subescalas:

- HAD - ansiedade: sem ansiedade de 0 a 8, com ansiedade $\geq$ a 9 (maior ou igual);

- HAD - depressão: sem depressão de 0 a 8, com depressão $\geq$ a 9 (maior ou igual).

Observou-se um empate na escala de ansiedade: 50\% dos alunos apresentam ansiedade e 50\% não apresentam. Na escala de depressão, 56\% dos alunos apresentaram depressão em relação à atuação profissional e acadêmica, e $44 \%$ não a apresentaram.

Os alunos que apresentaram ansiedade e depressão foram avaliados individualmente, para verificar o foco que os leva a apresentarem tais problemas. Estas avaliações foram feitas por meio de consultas semanais com a psicóloga do serviço. A principal abordagem visava à verificação da melhoria do comportamento emocional do aluno no ambiente profissional e na vida pessoal por meio da diminuição da angústia, da ansiedade, da depressão, da falta de determinação e organização, assim como à verificação de alguns problemas de ordem pessoal que pudessem desencadear tais comportamentos. Estes alunos foram estimulados a continuar o tratamento psicoterápico.
Os alunos com média abaixo de 5,0 apresentavam como motivos principais para não terem atingido a média no provão $(6,0)$ - que envolve uma prova escrita com 100 questões e provas práticas de tomografia computadorizada, ultrassonografia, mama e RX - e também para o desenvolvimento de ansiedade e depressão a falta de tempo para o estudo por causa do excesso de trabalho, assim como problemas pessoais e de relacionamento com familiares, gravidezes e falta de organização do tempo relacionado ao trabalho, estudo, lazer e atenção à família. Já os alunos com média acima de 7,0 não apresentaram ansiedade nem depressão.

\section{DISCUSSÃO}

Segundo Gonçalves apud Millan et al. ${ }^{8}$, o professor precisa apresentar ao estudante conhecimentos básicos e proporcionar o desenvolvimento de habilidades técnicas; estimular o aluno a pensar claramente; conscientizar para necessidades comunitárias; mostrar organização e clareza, além do conhecimento dos métodos institucionais; ter postura pedagógica e abordagem didática adequadas ao que se propõe.

Neste estudo, foi verificado que a maior parte dos médicos percebe no chefe do serviço todos esses aspectos, sendo que a relação baseada no suporte dado com sensibilidade e honestidade no relacionamento chefe-aluno tem maior peso. Em relação ao estafe, os médicos notam que a função do professor é exercida em sua plenitude, formando excelências. Os próprios alunos avaliaram seus preceptores como tendo excelente padrão de qualificação, competência, alto nível de conhecimento, dedicação, disponibilidade para ajudar, excelente didática, atenção e objetividade.

Segundo Silva et al. ${ }^{10}$, a preceptoria em programas de Residência Médica facilita a transição entre o aluno de curso de pós-graduação e sua prática profissional. Portanto, a função do preceptor deve ser ressaltada e seus atributos devem ser motivo de discussão e de reflexão no sentido de atender às necessidades e anseios dos médicos residentes.

Para Borus ${ }^{11}$, a Residência Médica determina várias mudanças tanto na vida pessoal como na vida profissional do indivíduo. Muitos médicos residentes mudam de cidade para cursar programas em outros locais, necessitando de rápida adaptação à nova instituição. Vários sofrem com a tensão no ambiente de trabalho, pois têm receio de contrair o vírus da imunodeficiência adquirida, da hepatite ou de outra doença, além do temor de ação judicial em decorrência de má prática profissional. A incidência de depressão, ideias de suicídio e dependência química não é desprezível. O preceptor deve desenvolver competências e habilidades para lidar com tais situações. 
Segundo Silva et al.$^{10}$, a imagem do preceptor que fica para um aluno pode ser positiva ou negativa, dependendo da impressão deixada por ele. Experiência, conhecimento, interesse, competência, didática e humildade são o que se espera dele. Entretanto, a arrogância é o maior ponto negativo de um preceptor.

Não se pode menosprezar o bom relacionamento dos alunos com os profissionais de apoio integrantes do serviço, o que também pode ocasionar uma diferença na formação do jovem médico ao fazê-lo sentir no ambiente de trabalho a continuação do próprio lar. Neste estudo, foi observado que os alunos da Radiologia e Diagnóstico por Imagem têm bom relacionamento com as secretárias do serviço, pois estas sempre são educadas, atenciosas, prestativas, solícitas e esclarecem dúvidas em relação ao serviço.

Para Martins ${ }^{12}$, os médicos residentes enfrentam situações de estresse que envolvem temores em relação a cometer erros devido a fadiga, falta de tempo, muita responsabilidade, falta de organização pessoal, além do nível de cobrança pessoal quanto à determinação na Residência Médica. Mesmo tendo bom nível de aprendizagem e estímulo para estudar por meio dos seminários, que considera excelentes, a maioria dos estudantes citou esses fatores. Eles alegam não ter maior aproveitamento por falta de tempo para os estudos ou por se sentirem ansiosos ou desanimados, pois a maior parte dos médicos entrevistados só dispõe de, no máximo, duas horas diárias para os estudos.

Segundo De Marco ${ }^{7}$, o estresse atinge seu ápice na Residência Médica, pois existe a transição aluno-médico, excesso de responsabilidade, pouco contato social, exaustão, privação de sono, muito trabalho, medo de errar. Tudo isso pode levar a estados depressivos, ideação suicida, excesso de consumo de álcool, drogas e medicamentos de fácil acesso. De acordo com a Associação Médica Americana, os médicos residentes constituem um grupo de risco para distúrbios emocionais e comportamentais. Entre eles, a depressão, a ansiedade e a privação do sono são os mais importantes fatores estressantes.

Para Mello Filho ${ }^{13}$, além desses temores, há o medo da falta de realização profissional e inseguranças em relação ao mercado de trabalho. Este fato faz com que muitos estudantes procurem a Residência Médica como uma forma de permanecer por um período maior como estudantes, obtendo orientação e suporte de um professor. Porém, isto gera mais angústia, ansiedade, estresse e depressão, pois não se sentem capazes de ter autonomia profissional.

Entre as angústias mais encontradas está o dilema vida e morte. E a angústia de, muitas vezes, não poder evitá-lo origina o sentimento de impotência, encontrado com frequência em situações de pacientes terminais e crônicos, na carência de recursos da instituição e devido à instabilidade emocional do aluno.
Conforme Mielnik ${ }^{14}$, aspectos emocionais são manifestações ligadas às reações globais intensas e rápidas do organismo em resposta a uma estimulação inesperada. As emoções estão estreitamente ligadas às necessidades psicológicas fundamentais, às motivações, e podem acarretar moléstias mentais ou psicossomáticas.

Borges ${ }^{15}$ reforça que, além das situações diárias que os médicos residentes e especializandos têm que enfrentar para conseguir lidar com as inúmeras emoções conflitantes, o desempenho acadêmico e as motivações destes são fatores que podem gerar mais ansiedade e depressão, pois os níveis motivacionais estão ligados diretamente ao desempenho acadêmico, ao significado do trabalho desses médicos residentes e, consequentemente, ao desempenho profissional. A motivação em relação ao seu desempenho pode ser verificada, muitas vezes, como algo que requer muito esforço físico, pressa e atarefamento, o que gera um desgaste físico e mental de grande porte. Em alguns casos, estes indivíduos chegam a se comparar com uma máquina.

Segundo Millan ${ }^{8}$, o médico residente pode ser considerado emocionalmente desajustado quando se torna frio, o que o leva a se afastar da família; quando se torna insubstituível, o que gera isolamento social, pois só vive para o trabalho; quando tem um humor negro, o que demonstra incapacidade de lidar com as frustrações e tristezas relacionadas à profissão; quando nega que existe algum problema ou limites inseparáveis da sua profissão, o que o torna ainda mais arrogante, estereotipado e rígido; quando assume o papel de "curador", se automedica, passa diagnóstico a familiares, é onipotente, entre outras características.

Alguns autores ainda citam que existe uma prevalência alta de suicídios, abuso de substâncias psicoativas, tensão, ansiedade, deterioração, burnout e deficiência orgânica, como também taxas altas de depressão $0^{16,17}$.

Para Maslach e Jackson apud Lima et al. ${ }^{18}$, burnout é uma síndrome de exaustão emocional, despersonalização e reduzida realização profissional que pode ocorrer entre indivíduos que trabalham com pessoas. A exaustão emocional diz respeito à falta ou carência de energia e um sentimento de esgotamento emocional. A despersonalização reflete o desenvolvimento de atitudes frias, negativas e insensíveis; é a dureza ao responder às pessoas receptoras de um serviço prestado, traduzindo a desumanização, a hostilidade, a intolerância e o tratamento impessoal, com burnout para com seus clientes, colegas e superiores. Por fim, a sensação de baixa realização profissional evidencia a diminuição do sentimento de competência em relação ao trabalho com pessoas; tendem a acreditar que seus objetivos profissionais não foram atingidos e 
vivenciam uma sensação de insuficiência e baixa autoestima profissional.

Em estudos realizados por Bjorksten et al. ${ }^{19}$, observou-se que os médicos residentes se sentiam apáticos, insatisfeitos consigo mesmos, tímidos, inibidos, sozinhos, queixosos em relação à rigidez das normas e horários do serviço e por terem poucas horas de sono. A falta de vida social foi responsabilizada por muito destes problemas.

Com a aplicação da Escala Hospitalar de Ansiedade e Depressão (HADS) pode-se observar o que foi citado: a maioria dos médicos residentes e especializandos apresenta tanto ansiedade como depressão, decorrentes dos problemas organizacionais, bem como problemas de nível socioeconômicofamiliar vividos no dia a dia.

Outros trabalhos, como, por exemplo, o de Snaith ${ }^{20}$, confirmaram a validade da HADS na utilização para a qual foi projetada. É confiável e está disponível em muitos idiomas.

O Serviço de Psicologia foi incluído neste estudo desde o princípio, acompanhando estes alunos semanalmente e atuando para diminuir a angústia, a ansiedade, a depressão, a falta de determinação e organização, assim como algumas fontes que podem desencadear tais problemas, provenientes de conflitos nos âmbitos profissional e pessoal.

\section{CONCLUSÃO}

O baixo desempenho acadêmico e profissional está ligado à vivência de um processo estressor, desencadeado por falta de determinação e organização dos alunos, e problemas socioeconômicos e familiares que originam um processo ansiogênico e/ou depressivo, desestruturando o desempenho esperado pelo médico, professores e preceptores durante a sua especialização. Portanto, os responsáveis pela supervisão destes alunos devem ficar atentos ao diagnóstico precoce destes problemas e tentar solucioná-los com auxílio de psicólogos ou de outros profissionais especializados.

\section{REFERÊNCIAS}

1. Pereira Filho AS. Residência Médica. Rev Femina. Setembro 2001;29(8):489-90.

2. Brasil. Ministério da Educação. Secretaria de Educação Superior. Decreto n⿳0 80.281, de 05 de setembro de 1977. Regulamenta a Residência Médica, cria a Comissão Nacional de Residência Médica e dá outras providências. [acesso em 5 maio 2006]. Disponível em: http://portal.mec.gov.br/ sesu/arquivos/pdf/d80281.pdf

3. Brasil. Ministério da Educação. Secretaria de Educação Superior. Comissão Nacional de Residência Médica. Resolução CNRM no 02, de 17 de maio de 2006. Dispõe sobre
Requisitos Mínimos dos Programas de Residência Médica e dá outras providências. [acesso em 24 set. 2006]. Disponível em: http://portal.mec.gov.br/sesu/arquivos/pdf/ cnrm/resolcnrm002_2006.pdf

4. Brasil. Ministério da Educação. Conselho Nacional de Educação. Resolução no 1 de 8 de junho de 2007. Estabelece normas para o funcionamento de cursos de pós-graduação lato sensu, em nível de especialização. Diário Oficial da União. Brasília, 8 ago. 2007; Seção 1, p. 09.

5. Brasil. Lei $n^{\circ}$ 6932, de 7 de julho de 1981. Dispõe sobre as atividades do médico residente e dá outras providências. Diário Oficial da União, Brasília, 9 de julho de 1981. Seção 1, p. 12789-90. [acesso em 22 maio 2007]. Disponível em: http://www81.dataprev.gov.br/sislex/paginas/42/1981/6932.htm

6. Glasser W. Teoria da Escolha: uma nova psicologia de liberdade pessoal: São Paulo: Ed. Mercuryo; 2001.

7. De Marco MA. A Face Humana da Medicina. São Paulo: Casa do Psicólogo; 2003.

8. Millan LR, De Marco OLN, Rossi E, Arruda PCV. O Universo Psicológico do Futuro Médico: vocação, vicissitude e perspectiva. São Paulo: Casa do Psicólogo; 1999.

9. Zigmond AS, Snaith RP. The Hospital Anxiety and Depression Scale. Acta Psychiatr Scand. 1983;67:361-70.

10. Silva GCC, Sousa EG, Koch HA. Atributos de preceptores de programas de Residência édica. Rev Bras Educ Med. 2008; 32(2 supl. 2):37 [Trabalho apresentado no 46 Congresso Brasileiro de Educação Médica; 2008 out.18-21; Salvador].

11. Borus JF. Recognizing and managing residents' problems and problem residents. Acad Radiol. 1997;4(7):527-33.

12. Martins LAN. Residência Médica: estresse e crescimento. São Paulo: Casa do Psicólogo; 2005.

13. Mello Filho J. Psicossomática Hoje. Porto Alegre: Artes Médicas; 1992.

14. Mielnik I. Dicionário de Termos psiquiátricos. São Paulo: Roca; 1987.

15. Borges LO. Os Profissionais de Saúde e seu Trabalho. São Paulo: Casa do Psicólogo; 2005.

16. Mawardi BH. Satisfactions, dissatisfactions, and causes of stress in medical practice. JAMA. 1979;241(14):1483-6.

17. Peterlini M, Tibério IF, Saadeh A, Pereira JC, Martins MA. Anxiety and depression in the first year of medical residency training. Med Educ. 2002;36(1):66-72.

18. Lima FD, Buunk AP, Araujo MBJ, Chaves JGM, Muniz DLO, Queiroz LB. Síndrome de Burnout em Residentes da Universidade Federal de Uberlândia - 2004. Rev Bras Educ Med. 2007;31(2):137-46. 
19. Bjorksten O, Sutherland S, Miller C, Stewart T. Identification of medical student problems and comparison with those other students. Med Educ. 1983;58:759-67.

20. Snaith RP. The Hospital Anxiety and Depression Scale. Health Qual Life Outcomes [periódico na internet]. 2003, [acesso em 2009 jul. 2]. Available at: http://www.hqlo. com/content/1/1/29

\section{CONTRIBUIÇÃO DOS AUTORES}

Glauce Cerqueira C da Silva participou de forma total em todas as áreas deste estudo, juntamente com os co-autores. Hilton Augusto Koch participou como orientador oficial na pesquisa bibliográfica, na concepção e desenho do estudo, assim como da redação deste texto. Evandro Guimarães de Sousa participou no desenho deste estudo e na interpretação dos dados, assim como da redação deste texto. Emerson Gas- paretto participou na concepção e desenho deste estudo, como orientador na metodologia e na redação deste texto. Rogério Christiano Buys participou como orientador na pesquisa bibliográfica do estudo, na área da Psicologia e na redação deste texto.

\section{CONFLITO DE INTERESSES}

Declarou não haver.

\section{ENDEREÇO PARA CORRESPONDÊNCIA}

Glauce Cerqueira Corrêa da Silva

Rua Marquês de Paraná, 62 - apto 401

Flamengo - Rio de Janeiro

CEP 22230-030 - RJ

E-mail: glauce@centroin.com.br 